\title{
PHYSIO-BIOCHEMICAL CHARACTERISTICS AND CORRELATION ANALYSIS OF THE SEEDS OF SOME COTTON (GOSSYPIUM HIRSUTUM L.) GENOTYPES UNDER COLD TEMPERATURE STRESS
}

\author{
XIA, J. ${ }^{1 \#}-$ KONG, X. $.^{2 \#}-$ SHI, X. ${ }^{1}-$ HAO, X. ${ }^{1}-$ LI, N. ${ }^{1}-$ KHAN, A. ${ }^{1}-$ LUO, H. ${ }^{1 *}$ \\ ${ }^{1}$ Key Laboratory of Oasis Eco-Agriculture, Xinjiang Production and Construction Group, \\ Shihezi University, 832003 Shihezi, Xinjiang, China \\ ${ }^{2}$ Cotton Institute, Xinjiang Academy of Agricultural and Reclamation Science, 832003 Shihezi, \\ Xinjiang, China \\ ${ }^{\#}$ These authors contributed equally to this work \\ *Corresponding author \\ e-mail: Luohonghai79@163.com \\ (Received $18^{\text {th }}$ Jun 2019; accepted $14^{\text {th }}$ Nov 2019)
}

\begin{abstract}
Cotton seed germination and seedling development is severely restricted, when the seed is exposed to low temperature stress. It is urgently needed to explore cotton seed germination characteristics and the mechanism involved in low temperature stress tolerance. Different cotton genotypes (Upland cotton Xinluzao65 and Island cotton Xinhai35), and three temperatures levels i.e. $12-15^{\circ} \mathrm{C}, 18-21^{\circ} \mathrm{C}$ and $25-28{ }^{\circ} \mathrm{C}$ (CK) were studied to explore germination characteristics, antioxidant enzymes activities and osmotic adjustment substances responses. The results show that with the decline of temperature, germination characteristics, cold resistance index and that water absorption of cotton seeds significantly decreased at $(P<0.05)$, and XH35 shows stronger resistance to cold. The activities of antioxidant enzymes and osmotic adjustment substances of cotton seeds were substantially increased under low temperature. Superoxide dismutase (SOD), peroxidase (POD), catalase (CAT) activities, soluble protein (SP), soluble sugar (SS) and free proline (FP) contents of XH35 were increased by 31.06\%, 17.03\%, 12.33\%, 23.80\%, 9.63\%, and $5.36 \%$, respectively than those of XLZ65. The principal component analysis revealed that SS and FP are the main drivers, hindering cotton seeds germination. Therefore, Island cotton shows a higher cold resistance by increasing water absorption rate, antioxidant enzyme activities and osmotic adjustment.
\end{abstract}

Keywords: seed germination characteristics, water absorption rate, correlation analysis, principle component analysis

\section{Introduction}

Cotton (Gossypium hirsutum L.) is the world's leading crop as it provides fiber and oil. Even though it has been introduced to temperate zones at high latitudes, it still shows sensitivity to low temperature stress (Barrero-Gil and Salinas, 2013). Xinjiang is rich in light and heat and is one of the major cotton planting areas in China, accounting for $19.77 \%$ of global cotton production (Chen et al., 2017). According to the meteorological data in the past years, damages caused by low temperature $\left(7.72 \sim 10.52{ }^{\circ} \mathrm{C}\right)$ in the cotton seeding time (April-May) in Xinjiang occur frequently, and the area reseeded, destroyed and replanted each year accounts for 5 to12\% of the total cotton planting area (Wu et al., 2012). The low temperature has become one of the main factors affecting the efficient production of cotton (Khan et al., 2017; Wang et al., 2016a). Therefore, it has become one of the most important problems for sustainable 
cotton production and cotton breeding program. It is essential to identify physiological responses of cotton seeds and the mechanism involved in low temperature tolerance.

The optimal growth temperature for cotton is $20 \sim 30{ }^{\circ} \mathrm{C}$, however, when the daily temperature average is lower than $15^{\circ} \mathrm{C}$, the growth of cotton will be inhibited (Barrero-Gil and Salinas, 2013b; Ashraf, 2002), especially during the germination and seedling phases (Chen, 2003). Lauterbach (1999) concludes that the minimum temperature for germination of cotton seeds is $10.5 \sim 12{ }^{\circ} \mathrm{C}$. Wang et al. (2016b) can effectively identify cotton cold resistance in its cotyledon stage according to the fact that the cotton can grow as normal when it undergoes low temperature treatment of $4{ }^{\circ} \mathrm{C}$ in its cotyledon stage. The response of cotton of different genotypes also differs largely in the seedling phases. Seedlings of high-cold-resistant cotton have more sensitive and efficient active oxygen scavenging capacity and osmotic adjustment response mechanism in low temperature. At the same time, the resistance to low temperature of cotton seedlings is enhanced by maintaining a high photosynthetic rate (Wu et al., 2014). Yan et al. (2016) used 17 cotton varieties in three major (Yangtze River, Yellow River and Northwest Inland) cotton growing areas as experimental materials, and it was found that low temperature stress could significantly weaken the correlation between seed vigor and physical characteristics. Therefore, it is important to know the physiological mechanism for responding to low temperature of cotton seeds of different cold-tolerant genotypes in terms of germination, which plays a pivotal role in working out cold-resistant cultivation measures and breeding cold-tolerant varieties.

Island cotton (Gossypium barbadense) has better comprehensive tolerance and excellent fiber properties, and is an important raw material for top-grade and special cotton textiles (Liu et al., 2015). Xinjiang is the only growing area for Island cotton in China due to its suitable light and heat conditions. The perennial planting area is $100,000 \mathrm{hm}^{2}$, and its total output accounts for about a quarter of the world's ELS (including Egyptian long-staple cotton with its velvet length $\leq 35 \mathrm{~mm}$ ) (Tian et al., 2014). At present, the research on cold tolerance of Island cotton in low temperature mainly focuses on seedling stage, flowering and boll stage (Sawan et al., 2011; Yan et al., 2019), and fiber quality (Mei et al., 2012; Avci et al., 2013). However, it has not been systematically studied to transform ingredients and physiological regulation mechanism in the germination of cotton seeds, especially the physiological mechanism for responding to low temperature of cotton seeds of different cold-tolerant genotypes (Island cotton and Upland cotton) in terms of germination.

Therefore, the objectives of this experiment are (i) to study the germination index of different genotypes (Island cotton and Upland cotton) under low temperature stress, (ii) to analyze the antioxidant enzyme activity, osmotic adjustment substance content and membrane lipid peroxidation products dynamic changes and intrinsic relationship under low temperature stress, and (iii) to clarify the intrinsic relationship between the germination characteristics, physiological indexes of cotton seeds and the cold tolerance of cotton varieties; it is expected to provide a theoretical basis for studying the cold resistance mechanism of cotton and the breeding of low temperature resistant cotton varieties.

\section{Materials and methods}

\section{Plant materials}

Cotton varieties of different genotypes: Xinluzao65 (Upland Cotton) and Xinhai35 (Island Cotton) were used. These materials were obtained from Cotton Institute of 
Xinjiang $\left(45^{\circ} 22^{\prime} 43.4^{\prime \prime} \mathrm{N}, 84^{\circ} 50^{\prime} 32.5^{\prime \prime} \mathrm{E}\right)$ Academy of Agricultural Sciences. The experiment was carried out in the artificial climate chamber (GXZ-208B, Ningbo Jiangnan Instrument Factory, China) of Shihezi University. The biological characteristics of cotton seeds of different genotypes are shown in Table 1. The content of protein, adipose, and starch in Xinhai35 (XH35, Table 2) is respectively $19.02 \%$, $50.85 \%$ and $4.83 \%$ higher than those of Xinluzao65 (XLZ65), grain weight and seed vigor of XH35 are $20.02 \%, 6 \%$ higher than those of XLZ65, respectively, but water content of XH35 is 56.2\% lower than that of XLZ65. Preliminary experiments showed that different genotypes of cotton had different germination effects under low temperature stress (Fig. 1).

\section{Experimental design}

Three temperature levels i.e. $12-15{ }^{\circ} \mathrm{C}, 18-21{ }^{\circ} \mathrm{C}$ and $25-28^{\circ} \mathrm{C}$ (Table 2) were targeted. During the test, the environment of cotton seed germination under field conditions was simulated in the artificial climate chamber (GXZ-208B, Ningbo Manufacturing Factory, Zhejiang, China), where the relative humidity was $50 \%$, the light/dark ratio was $14 \mathrm{~h} / 10 \mathrm{~h}$ and the light intensity was $283 \mu \mathrm{mol} \mathrm{m}^{-2} \mathrm{~s}^{-1}$. Cotton seeds with full grain, intact embryo, no mildew and of same size were selected for the experiment. Seeds were sterilized in $200 \mathrm{ml}$ of $1 \%$ potassium permanganate for 3 to 5 min, and then rinsed with deionized water for 3 to 4 times. After that, seeds were placed neatly in Petri dishes $(\varphi=15 \mathrm{~cm})$ with 2 layers of filter paper (GB/T1914-93, Hangzhou Xinhua Paper Ltd., China), 50 seeds in each dish. The sterile distilled water was added until saturation. The dishes were placed in climatic chambers at $15 / 12{ }^{\circ} \mathrm{C}, 21 / 18^{\circ} \mathrm{C}$ and $28 / 25^{\circ} \mathrm{C}$, respectively, to test germination. Each treatment was repeated 5 times, and every $24 \mathrm{~h} 5 \sim 10 \mathrm{ml}$ distilled water was added.

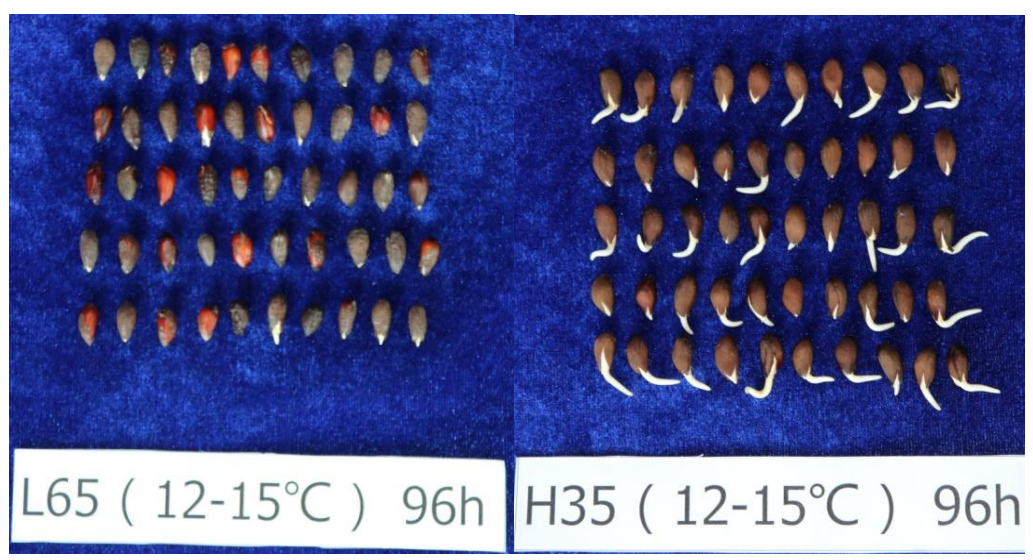

Figure 1. The picture of two cotton seeds germinations (Xinluzao65 seed on the left and Xinhai35 on the right)

Table 1. Biological characteristics of different genotypes of cotton seeds

\begin{tabular}{c|c|c|c|c|c|c}
\hline Variety & $\begin{array}{c}\text { Seed mass } \\
(\mathbf{g} / \mathbf{1 0 0})\end{array}$ & $\begin{array}{c}\text { Water } \\
\text { content }(\boldsymbol{\%})\end{array}$ & $\begin{array}{c}\text { Seed vigor } \\
(\boldsymbol{\%})\end{array}$ & $\begin{array}{c}\text { Protein } \\
(\mathbf{m g} / \mathbf{g})\end{array}$ & $\begin{array}{c}\text { Adipose } \\
(\mathbf{m g} / \mathbf{g})\end{array}$ & $\begin{array}{c}\text { Starch } \\
(\mathbf{m g} / \mathbf{g})\end{array}$ \\
\hline Xinluzao65 (XLZ65) & $9.55 \pm 0.38$ & $8.17 \pm 1.02$ & 92 & $13.33 \pm 0.44$ & $0.29 \pm 0.027$ & $33.10 \pm 5.76$ \\
Xinhai35 (XH35) & $11.94 \pm 0.48$ & $5.23 \pm 0.43$ & 98 & $16.46 \pm 0.49$ & $0.59 \pm 0.032$ & $34.78 \pm 1.92$ \\
\hline
\end{tabular}

Values are presented as means \pm standard error $(n \geq 3)$ 
Table 2. The abbreviations of the treatment

\begin{tabular}{c|c|c}
\hline \multirow{2}{*}{ Temperature } & \multicolumn{2}{|c}{ Varieties } \\
\cline { 2 - 3 } & Xinluzao65 (XLZ65) & Xinhai35 (XH35) \\
\hline $12-15{ }^{\circ} \mathrm{C}$ & $\mathrm{L} 12$ & $\mathrm{H} 12$ \\
$18-21{ }^{\circ} \mathrm{C}$ & $\mathrm{L} 18$ & $\mathrm{H} 18$ \\
$25-28{ }^{\circ} \mathrm{C}(\mathrm{CK})$ & $\mathrm{L} 25$ & $\mathrm{H} 25$ \\
\hline
\end{tabular}

\section{Test items and methods}

\section{Determination of germination index}

It is taken as germination when germ is longer than $1 / 2$ of the cotton seed. The number of germinated seeds was counted daily from the first day. The following parameters were determined: Germination rate $(\%)=$ (number of all germinated seeds during the germination test / number of cotton seeds tested) $\times 100 \%$; Germination potential $(\%)=$ (number of normally germinated seeds within $96 \mathrm{~h} /$ number of cotton seeds tested $) \times 100 \%$; Germination index $(\mathrm{GI})=\sum \mathrm{Gt} / \mathrm{Dt}$, Mean time of germination $(\mathrm{MTG})=\sum(\mathrm{GtDt}) / \sum \mathrm{Gt}$, while Gt refers to the germination rate at $\mathrm{t}$ and Dt refers to germination days; Water absorption rate $(\%)=($ wet weight-dry weight $) /$ dry weight $\times 100 \%$; Germination index $=1.00 \times \mathrm{n} 3+0.75 \times \mathrm{n} 5+0.5 \times \mathrm{n} 7+0.25 \times \mathrm{n} 9(\mathrm{n} 3, \mathrm{n} 5, \mathrm{n} 7, \mathrm{n} 9$ represent the seed germination rate on the 3rd, 5th, 7th and 9th day respectively); Seed germination cold resistance index $=$ germination index in low temperature/control germination index.

\section{Measurement of physiological index of germination}

The sampling time was determined according to the water uptake rate of cotton seeds. At the temperature of $25 \sim 28{ }^{\circ} \mathrm{C}$, seeds were sampled at: $2 \mathrm{~h}, 4 \mathrm{~h}, 6 \mathrm{~h}, 12 \mathrm{~h}$ $(0.5 \mathrm{~d}), 24 \mathrm{~h}(1 \mathrm{~d}), 48 \mathrm{~h}(2 \mathrm{~d})$; at the temperature of $18 \sim 21{ }^{\circ} \mathrm{C}$, seeds were sampled at: 2 h, 4 h, 6 h, 12 h (0.5 d), 24 h (1 d), 48 h (2 d), 72 h (3 d), 96 h (4 d); at the temperature of $12 \sim 15{ }^{\circ} \mathrm{C}$, seeds were sampled at: $2 \mathrm{~h}, 4 \mathrm{~h}, 6 \mathrm{~h}, 12 \mathrm{~h}(0.5 \mathrm{~d}), 24 \mathrm{~h}(1 \mathrm{~d}), 48 \mathrm{~h}(2 \mathrm{~d}), 72$ h ( $3 \mathrm{~d}), 96 \mathrm{~h}(4 \mathrm{~d}), 120 \mathrm{~h}(5 \mathrm{~d})$. About 50 cotton seeds weighing 4 6 g were taken and frozen with liquid nitrogen directly at $-80^{\circ} \mathrm{C}$. With the seed coats removed, enzymes were extracted to test activity; the samples were put in $10 \mathrm{ml}$ container and then ground using a freezing grinder for $45 \mathrm{~s}$, and they were used to measure the content of soluble sugar (SS), soluble protein (SP), free proline (FP), malondialdehyde (MDA) and hydrogen peroxide $\left(\mathrm{H}_{2} \mathrm{O}_{2}\right)$, as well as the activities of superoxide dismutase (SOD), peroxidase (POD) and catalase (CAT).

\section{Antioxidant enzymes (SOD, POD, and CAT) activities in seed}

The activities of enzymatic antioxidants viz., SOD, POD, and CAT in seed were assessed according to the standard procedure (Kochba et al., 1977; Kraus and Fletcher, 1994). The SOD activity was the amount of extract that gave $50 \%$ inhibition in nitrotetrazolium blue chloride (NBT) photoreduction detected at $560 \mathrm{~nm}(\mathrm{Q} / \mathrm{YXLZ82,}$ Shanghai Precision Science Instrument Co., Ltd. China). The POD activity was based on the determination of guaiacol oxidation at $470 \mathrm{~nm}$ by $\mathrm{H}_{2} \mathrm{O}_{2}$ and was presented as $\mu \mathrm{mol} \mathrm{H} \mathrm{O}_{2} \mathrm{~g}^{-1}(\mathrm{FW})$. The change in absorbance at $470 \mathrm{~nm}$ was recorded every min by a spectrophotometer. One unit of POD activity is the amount of enzyme that causes the decomposition of $1 \mu \mathrm{g}$ substrate at $470 \mathrm{~nm}$ for $1 \mathrm{~min}$ in $1 \mathrm{~g}$ fresh sample at $37^{\circ} \mathrm{C}$. The 
CAT activity was measured using the $0.5 \mathrm{~g}$ fresh seed sample. The CAT activity was defined as the amount of enzyme that causes the decomposition of $1 \mu \mathrm{mol} \mathrm{H}_{2} \mathrm{O}_{2}$ at $405 \mathrm{~nm}$ per min in $1 \mathrm{~g}$ fresh sample at $37^{\circ} \mathrm{C}$.

\section{Osmotic adjustment substance (SS, SP, and FP) contents in seed}

$0.5 \mathrm{~g}$ seed germ powder was put in a $10 \mathrm{ml}$ centrifuge tube, $5 \mathrm{ml} 80 \%$ ethanol solution was added to it, and then it was kept in a water bath at $80{ }^{\circ} \mathrm{C}$ for $30 \mathrm{~min}$, then cooled to room temperature and centrifuged at $4000 \mathrm{rpm}$ for $10 \mathrm{~min}$, and then $2 \mathrm{ml}$ of supernatant was taken and mixed well with anthrone-sulfuric reagent. The mixture was heated in a boiling water bath at $100{ }^{\circ} \mathrm{C}$ for $10 \mathrm{~min}$, and the absorbance was measured at $620 \mathrm{~nm}$ after cooling it to room temperature. SP was extracted by adding homogenized $0.5 \mathrm{~g}$ of seed germ powder in a $10 \mathrm{ml}$ centrifuge tube. The homogenate was centrifuged at $5000 \mathrm{rpm}$ for $10 \mathrm{~min}$, and then $0.1 \mathrm{ml}$ of the supernatant was thoroughly mixed with $0.9 \mathrm{ml}$ of distilled water and $5 \mathrm{ml}$ of Coomassie brilliant blue G-250 reagent; after 2 min, the absorbance was measured at $595 \mathrm{~nm}$. Free proline content of cotton seed was assayed by the method (Bates et al., 1973). The samples were homogenized in $5 \mathrm{~mL}$ of $3 \%$ sulfosalicylic acid and centrifuged at $6000 \mathrm{rpm}$ for $10 \mathrm{~min}$. Supernatant was heated with $2 \mathrm{~mL}$ of ninhydrin and glacial acetic acid at $100^{\circ} \mathrm{C}$ for $1 \mathrm{~h}$. The reaction was further extracted with $4 \mathrm{ml}$ of toluene by vigorous vortexing for $30 \mathrm{~s}$. The absorption of the chromophore was determined at $520 \mathrm{~nm}$ (Tecan-infinite M200, Switzerland).

\section{Lipid peroxidation ( $\mathrm{MDA}$ and $\mathrm{H}_{2} \mathrm{O}_{2}$ )}

Lipid peroxidation in cotton seed was determined as MDA content using the thiobarbituric acid method (Bailly et al., 1996). A $1.0 \mathrm{ml}$ aliquot of supernatant of tissue extract (seed) was mixed with $4 \mathrm{ml}$ of $20 \%(\mathrm{v} / \mathrm{v})$ trichloroacetic acid containing $0.5 \%(\mathrm{v} / \mathrm{v})$ thiobarbituric acid. The mixture was heated at $100{ }^{\circ} \mathrm{C}$ for $30 \mathrm{~min}$, and was cooled down and centrifuged at 10,000 rpm for $10 \mathrm{~min}$. The absorbance of the supernatant was assayed at 532 and $600 \mathrm{~nm} . \mathrm{H}_{2} \mathrm{O}_{2}$ content was determined according to Nakano and Asada (1987). $\mathrm{H}_{2} \mathrm{O}_{2}$ was extracted by homogenizing $0.5 \mathrm{~g}$ seed embryo powder in $3 \mathrm{ml}$ cold acetone. The homogenate was centrifuged at $3000 \mathrm{rpm}$ for $10 \mathrm{~min}$, with the supernatant mixed with 0.1 $\mathrm{mL} 5 \%(\mathrm{w} / \mathrm{v}) \mathrm{TiSO}_{4}$ and $0.2 \mathrm{~mL}$ ammonia water. After centrifuging the solution at 10,000 rpm for $5 \mathrm{~min}$, the precipitate was washed with acetone till the supernatant was colorless. The precipitate was solubilized in $3 \mathrm{ml}_{1} \mathrm{M} \mathrm{H}_{2} \mathrm{SO}_{4}$, with the absorbance measured at 415 $\mathrm{nm} . \mathrm{H}_{2} \mathrm{O}_{2}$ content was expressed as mmol g ${ }^{-1} \mathrm{FW}$.

\section{Data analysis}

Data were processed and mapped by Microsoft Excel 2010, R Studio, Origin and SigmaPlot 12.5. Single factor analysis of variance and correlation analysis were performed by SPSS 18.0. Significant difference examination was carried out using Duncan test at $(\alpha=0.05)$.

\section{Results}

\section{Effect of low temperature on germination index of cotton seeds}

The relative germination rate, relative germination potential, relative sprouting index, germination index and water absorption rate of the two cotton varieties decreased with 
the decline of temperature (Table 3 and 4). The average germination time shows an increasing trend under low temperature treatment, with obvious differences exiting in all control groups $(P<0.05)$. The germination rate, germination potential and germination index of XH35 are respectively $30.70 \%, 12.22 \%$ and $16.22 \%$ higher than those of XLZ65, and the water absorption rate of XH35 was significantly higher than that of XLZ65 $(P<0.05)$, which indicates that the water absorption rate is closely related to the germination of cotton seeds.

Table 3. Cotton seed germination temperature, germination time and cumulative germination rate

\begin{tabular}{c|c|c|c|c|c|c}
\hline \multirow{2}{*}{$\begin{array}{c}\text { Germination } \\
\text { time (t/h) }\end{array}$} & \multicolumn{3}{|c|}{ XLZ65 (\%) } & \multicolumn{3}{c}{ XH35 (\%) } \\
\cline { 2 - 7 } & $\mathbf{1 2 - 1 5}^{\circ} \mathbf{C}$ & $\mathbf{1 8 - 2 1}^{\circ} \mathbf{C}$ & $\mathbf{2 5 - 2 8}^{\circ} \mathbf{C}$ & $\mathbf{1 2 - 1 5}^{\circ} \mathbf{C}$ & $\mathbf{1 8 - 2 1}{ }^{\circ} \mathbf{C}$ & $\mathbf{2 5 - 2 8}^{\circ} \mathbf{C}$ \\
\hline 0 & 0 & 0 & 0 & 0 & 0 & 0 \\
24 & 0 & 0 & 3.33 & 0 & 0 & 9.33 \\
48 & 0 & 0 & 14.67 & 0 & 0 & 40.67 \\
72 & 0 & 3.33 & 72 & 0 & 18 & 83.33 \\
96 & 0 & 24 & 84 & 0 & 43.33 & 96 \\
120 & 0 & 46.67 & 89.33 & 0 & 68.67 & 97.33 \\
144 & 0 & 58.67 & 90.67 & 5.33 & 79.33 & 98 \\
168 & 0 & 64 & 90.67 & 18.67 & 85.33 & 98.67 \\
192 & 4 & 65.33 & 92 & 48 & 90 & 98.67 \\
216 & 10.67 & 67.33 & 92 & 76 & 92.67 & 98.67 \\
240 & 22 & 67.33 & 92 & 84.67 & 96.67 & 98.67 \\
264 & 28.67 & 67.33 & 92 & 84.67 & 96.67 & 98.67 \\
288 & 28.67 & 67.33 & 92 & 84.67 & 96.67 & 98.67 \\
312 & 28.67 & 67.33 & 92 & 84.67 & 96.67 & 98.67 \\
\hline
\end{tabular}

Table 4. Effect of low temperature stress on germination index of cotton seeds

\begin{tabular}{|c|c|c|c|c|c|c|c|}
\hline Treatment & $\begin{array}{c}\text { Germination } \\
\text { percentages } \\
(\%)\end{array}$ & $\begin{array}{c}\text { Germination } \\
(\%)\end{array}$ & $\begin{array}{c}\text { MTG } \pm \text { SE } \\
\text { (d) }\end{array}$ & $\begin{array}{c}\text { Germination } \\
\text { index } \pm \mathrm{SE}\end{array}$ & $\begin{array}{c}\text { Germination } \\
\text { index }\end{array}$ & $\begin{array}{l}\text { Cold } \\
\text { resistance } \\
\text { index }\end{array}$ & $\begin{array}{c}\text { Water } \\
\text { absorption } \\
\text { rate }(\%)\end{array}$ \\
\hline L12 & $28.67^{\mathrm{d}}$ & $0.00^{\mathrm{e}}$ & $9.32 \pm 0.80^{\mathrm{a}}$ & $1.49 \pm 0.31^{\mathrm{e}}$ & $0.05668^{c}$ & $0.0915^{\mathrm{d}}$ & $78.58^{c}$ \\
\hline L18 & $67.33^{\mathrm{c}}$ & $24.00^{\mathrm{d}}$ & $5.12 \pm 0.19^{c}$ & $6.98 \pm 0.78^{\mathrm{d}}$ & $1.1714^{\mathrm{b}}$ & $0.4287^{\mathrm{b}}$ & $83.3 b^{c}$ \\
\hline L25 & $92.00^{\mathrm{ab}}$ & $84.00^{\mathrm{b}}$ & $3.17 \pm 0.09^{\mathrm{d}}$ & $16.28 \pm 2^{\mathrm{b}}$ & $2.0733^{\mathrm{a}}$ & - & $86.14^{\mathrm{b}}$ \\
\hline $\mathrm{H} 12$ & $84.67^{\mathrm{b}}$ & $0.00^{\mathrm{e}}$ & $8.23 \pm 0.42^{b}$ & $5.27 \pm 0.13^{\mathrm{d}}$ & $0.2834^{c}$ & $0.2457^{c}$ & $88.33^{\mathrm{b}}$ \\
\hline H18 & $96.67^{\mathrm{a}}$ & $48.67^{c}$ & $4.73 \pm 0.18^{c}$ & $11.15 \pm 0.42^{\mathrm{c}}$ & $1.3534^{\mathrm{b}}$ & $0.5204^{\mathrm{a}}$ & $99.84^{\mathrm{a}}$ \\
\hline $\mathrm{H} 25$ & $98.67^{\mathrm{a}}$ & $96.00^{\mathrm{a}}$ & $2.66 \pm 0.32^{\mathrm{d}}$ & $21.43 \pm 1.93^{\mathrm{a}}$ & $2.3033^{\mathrm{a}}$ & - & $102.7^{\mathrm{a}}$ \\
\hline \multicolumn{8}{|c|}{ Source of variance } \\
\hline $\mathrm{T}$ & $1.23 \times 10^{-8 * * *}$ & $5.12 \times 10^{-7^{* * * *}}$ & $2.16 \times 10^{-10^{* * *}}$ & $1.58 \times 10^{-9 * * *}$ & $4.36 \times 10^{-5 * * *}$ & $1.84 \times 10^{-5 * * *}$ & $0.000896^{* * * *}$ \\
\hline $\mathrm{V}$ & $3.92 \times 10^{-9 * * *}$ & $0.00114^{* *}$ & $0.0119^{*}$ & $3.98 \times 10^{-5 * * *}$ & ns & $1.03 \times 10^{-6 * * *}$ & $2.74 \times 10^{-6 * * *}$ \\
\hline $\mathrm{T} \times \mathrm{V}$ & $1.65 \times 10^{-6 * * *}$ & ns & $\mathrm{ns}$ & $\mathrm{ns}$ & $0.0348^{*}$ & $0.0011^{* *}$ & ns \\
\hline
\end{tabular}

Values are presented as means \pm standard error $(n \geq 3)$. Lowercase letters represent significant differences after the same column of data $(p<0.05) . *, * *$ or $* * *$ indicates a significant $(p<0.05)$, extremely significant $(p<0.01)$ or very significant difference $(\mathrm{p}<0.001)$ between the treatments; “-" means none. The table below is the same. T: Temperature, V: Variety. L12 represents XLZ65 at the level of $12-15{ }^{\circ} \mathrm{C}, \mathrm{L} 18$ represents XLZ65 at the level of 18$21{ }^{\circ} \mathrm{C}$, L25 represents XLZ65 at the level of $25-28{ }^{\circ} \mathrm{C}(\mathrm{CK})$. H12 represents XH35 at the level of $12-15{ }^{\circ} \mathrm{C}, \mathrm{H} 18$ represents XH35 at the level of $18-21{ }^{\circ} \mathrm{C}, \mathrm{H} 25$ represents XH35 at the level of $25-28{ }^{\circ} \mathrm{C}(\mathrm{CK})$ 
According to the results of variance analysis, cotton seed germination indices at different temperatures show great variations. The germination rate, germination index, cold resistance index and water absorption rate of different varieties show significant differences. Germination index, the interactions between temperatures and variations are significantly different $(P<0.05)$, but there is no significant difference between the varieties. With the decrease of temperature, the germination cold resistance indices of the two cotton varieties significantly decreased, and show significant differences in temperatures and variations and their interactions. This indicates that cotton seeds of different genotypes show different cold resistance abilities.

\section{Effect of low temperature on protective enzyme activities in cotton seeds in process of imbibition}

The activity of SOD in the cotton seed embryos of XH35 is $10.00 \%$ higher than those of XLZ65. With the decrease of temperature, the activities of SOD enzyme under low temperature are higher than those of control groups at normal temperature (Fig. 2). The activity of SOD in XLZ65 embryos decreased with the time of low temperature and stress intensity. However, after $4 \mathrm{~h}$ of stress treatment, the activity of SOD of L12 and L18 are respectively $22.83 \%$ and $10.92 \%$ higher than that of L25 (Fig. 2A). The SOD activity of XH35 reaches a peak after $4 \mathrm{~h}$ of stress treatment (rapid water absorption phase), and increases respectively by $13.00 \%, 9.44 \%$ and $3.10 \%$ at different temperatures, especially after $24 \mathrm{~h}$ of imbibition, the enzyme activities of H25, H18, H12 increase respectively by $18.66 \%, 27.19 \%$ and $29.10 \%$, compared with those after $12 \mathrm{~h}$ of imbibitions (Fig. 2B).

Before imbibition, POD activity of XH35 (dry seeds) was $35.16 \%$ lower than that of XLZ65 (Fig. 2). Over imbibition time, the POD enzyme activity of XLZ65 treated by low temperature treatment was higher than that of control groups. After $12 \mathrm{~h}$ of imbibition, POD activity of L12 and L18 was $39.23 \%$ and $9.11 \%$ higher, respectively, than of L25 (Fig. 2C). The POD enzyme activity of XH35 increases starting from the initial imbibition phase. After $4 \mathrm{~h}$ of imbibition, the increase of POD enzyme activities of $\mathrm{H} 12$ and $\mathrm{H} 18$ are significantly different from that of $\mathrm{H} 25$, and $20.28 \%$ and $20.27 \%$ higher, respectively, than that of control groups. After $12 \mathrm{~h}$ of imbibition, no significant differences were observed among variations (Fig. 2D).

CAT activity was increased under low temperature during germination of cotton seeds, and the CAT activities between varieties showed significant differences (Fig. 2). After $2 \mathrm{~h}$ of stress treatment, the CAT activity of L12 increased, while that of L18 and L25 first decreased and then decreased. After $24 \mathrm{~h}$ of stress treatment (slow water absorption phase), the CAT activity of L12 and L18 was $26.83 \%$ and $33.98 \%$ higher than that of L25, which shows a significant difference (Fig. 2E). The CAT activity of XH35 greatly decreased at the initial stage of imbibition, and the decrease of that of $\mathrm{H} 25, \mathrm{H} 18$ and $\mathrm{H} 12$ were $47.23 \%, 46.59 \%$ and $37.64 \%$, respectively. After $24 \mathrm{~h}$ of imbibition, the CAT activity of $\mathrm{H} 12$ and $\mathrm{H} 18$ peaked $34.84 \%$ and $22.80 \%$ higher respectively than $\mathrm{H} 25$ (Fig. $2 F$ ).

\section{Effect of low temperature on osmotic adjustment substances in cotton imbibition process}

The content of soluble sugar (SS) decreased with imbibition, but the differences between the varieties were obvious at $4 \mathrm{~h}$ (Fig. 3). The content of SS increased in 
XLZ65 at $4 \mathrm{~h}$ under low temperature (Fig. 3A). The SS content of the XH35 decreased with the decline of temperature, that of H12, H18 and H25 increased at $6 \mathrm{~h}, 24 \mathrm{~h}$ and $4 \mathrm{~h}$, respectively. Whilst a rapid reduction was observed in $\mathrm{H} 25$ after $12 \mathrm{~h}$ of imbibition (Fig. 3B).

Under low temperature treatment, soluble protein (SP) content in XH35 seed embryos was 19.04\% higher than that in XLZ65's (Fig. 3). After imbibition for 2 to $4 \mathrm{~h}$, the content of SP decreases rapidly, and L12 was $22.68 \%$ higher than that of L25. However, no significant differences were noted after $4 \mathrm{~h}$ of imbibition (Fig. 3C). H35 had similar trend in SPA content with no obvious differences (Fig. 3D).

The content of free proline (FP) shows significant differences between varieties; under low temperature FP content increased (Fig. 3). After $6 \mathrm{~h}$ of imbibition, the content of FP in $\mathrm{H} 12$ and $\mathrm{H} 18$ increased respectively by $40.31 \%$ and $31.97 \%$, compared with that of H25 (Fig. 3F). The FP content of XLZ65 was significant, and after $6 \mathrm{~h}$ of imbibition, L12 and L18 resulted in the highest FP content (Fig. 3E).

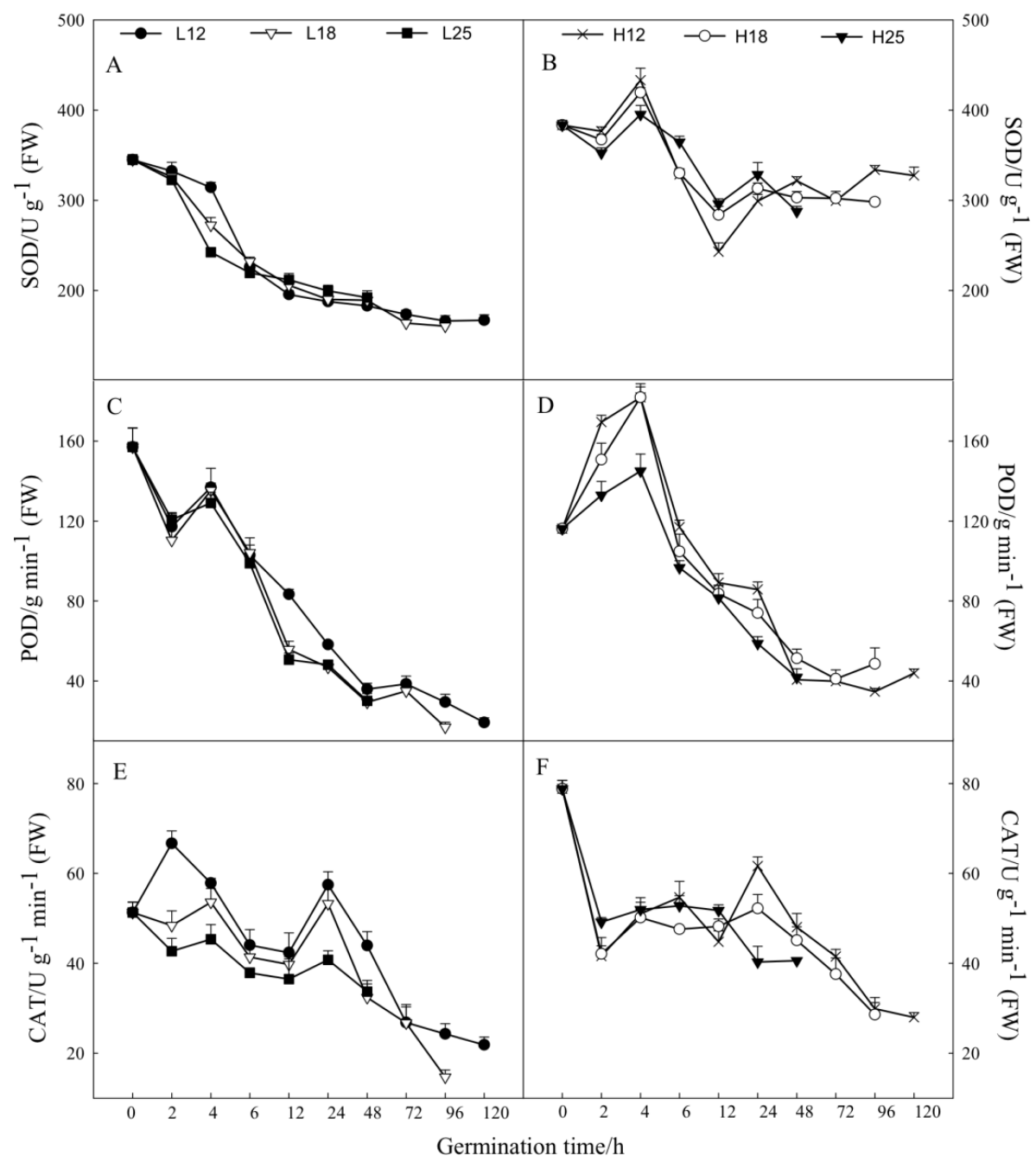

Figure 2. The dynamic change of low temperature stress on SOD, POD, CAT during cotton seed swelling. A, B, C, D, E, F represent respectively the changes of SOD, POD, CAT activities during the germination of XLZ65 and XH35 cotton. Bars indicate $S D(n=3)$. L12 represents $X L Z 65$ at the level of $12-15^{\circ} \mathrm{C}, \mathrm{L} 18$ represents XLZ65 at the level of $18-21{ }^{\circ} \mathrm{C}, \mathrm{L} 25$ represents

$X L Z 65$ at the level of $25-28^{\circ} \mathrm{C}(\mathrm{CK}) . \mathrm{H12}$ represents $\mathrm{XH} 35$ at the level of $12-15^{\circ} \mathrm{C}, \mathrm{H} 18$ represents XH35 at the level of $18-21^{\circ} \mathrm{C}, \mathrm{H} 25$ represents $\mathrm{XH} 35$ at the level of $25-28^{\circ} \mathrm{C}(\mathrm{CK})$ 


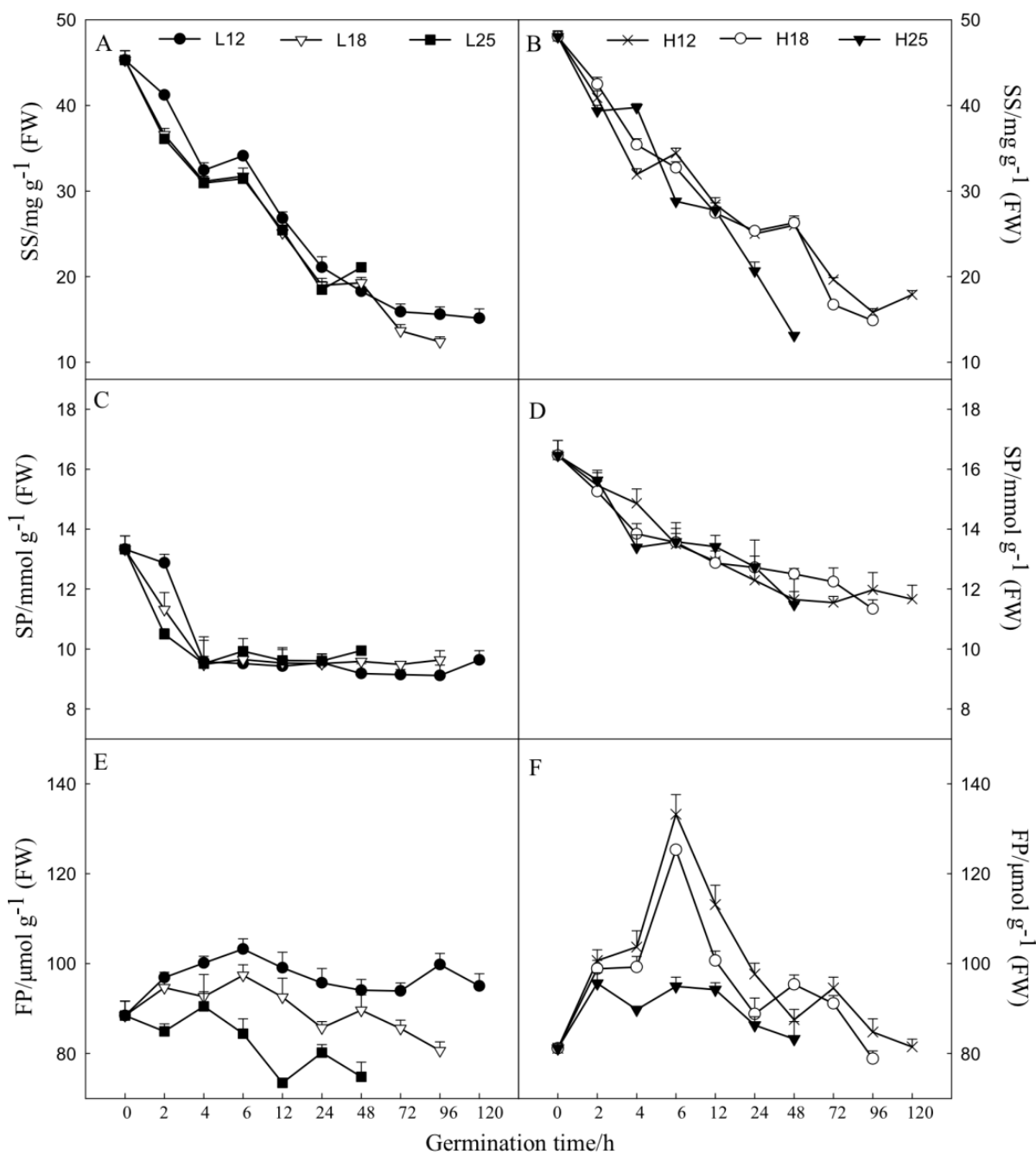

Figure 3. The dynamic change of low temperature stress on SS, SP, FP during cotton seed imbibition. $A, B, C, D, E, F$ represent respectively the changes of $S S, S P, F P$ contents during the germination of XLZ65 and XH35 cotton. Bars indicate $S D(n=3)$. L12 represents XLZ65 at the level of $12-15^{\circ} \mathrm{C}, \mathrm{L} 18$ represents XLZ65 at the level of $18-21^{\circ} \mathrm{C}, \mathrm{L} 25$ represents XLZ65 at the level of $25-28^{\circ} \mathrm{C}(\mathrm{CK}) . \mathrm{H} 12$ represents XH35 at the level of $12-15^{\circ} \mathrm{C}, \mathrm{H} 18$ represents XH35 at the level of $18-21^{\circ} \mathrm{C}, \mathrm{H} 25$ represents $\mathrm{XH} 35$ at the level of $25-28^{\circ} \mathrm{C}(\mathrm{CK})$

Effect of low temperature on the contents of hazardous substances (mda, $\left.\mathrm{h}_{2} \mathrm{o}_{2}\right)$ in cotton imbibition

With the decrease of temperature, the MDA content increased significantly compared with control (Fig. 4). After $2 \mathrm{~h}$ of imbibition, the MDA content of L12 and L18 increased by $64.83 \%$ and $62.15 \%$ respectively, while L25 increased by $15.09 \%$ (Fig. 4A). With the decrease of temperature, there is no significant increase in MDA content of XH35, and after $2 \mathrm{~h}$ of imbibition, the MDA content in its cotton seeds decreased significantly (Fig. 4B). Since the beginning of imbibition, the $\mathrm{H}_{2} \mathrm{O}_{2}$ content shows a significant decrease, and with the decrease of temperature, the $\mathrm{H}_{2} \mathrm{O}_{2}$ content was higher than that of control groups at normal temperature. At the initial stage of imbibition, the $\mathrm{H}_{2} \mathrm{O}_{2}$ content of $\mathrm{XH} 35$ was $28.55 \%$ higher than that of XLZ65 (Fig. 4). 


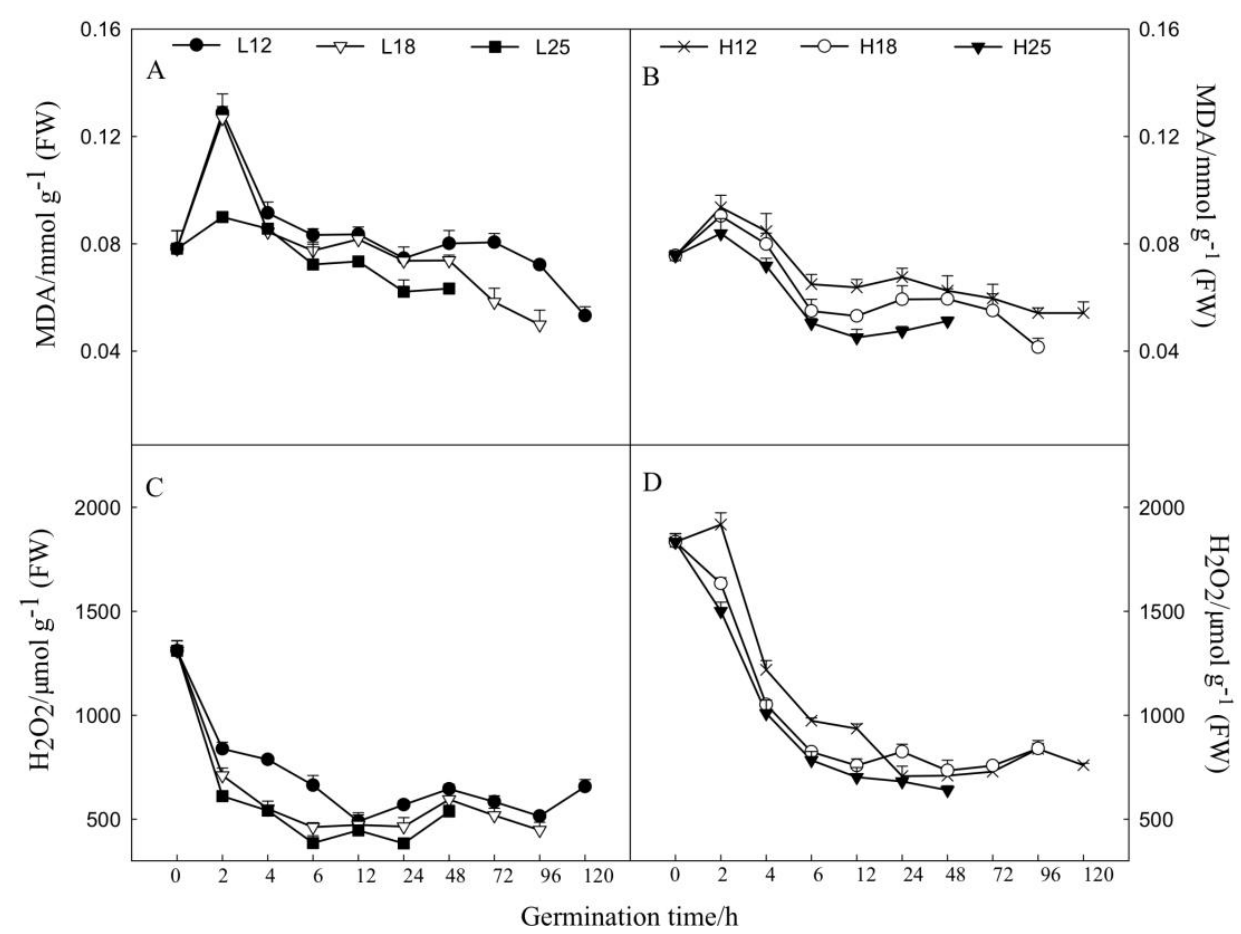

Figure 4. The dynamic change of low temperature stress on $M D A, \mathrm{H}_{2} \mathrm{O}_{2}$ during cotton seed imbibition. A, B, C, D represent respectively the changes of $M D A, \mathrm{H}_{2} \mathrm{O}_{2}$ contents during the germination of XLZ65 and XH35 cotton. Bars indicate $S D(n=3)$. L12 represents XLZ65 at the level of $12-15^{\circ} \mathrm{C}, \mathrm{L} 18$ represents XLZ65 at the level of $18-21^{\circ} \mathrm{C}, \mathrm{L} 25$ represents XLZ65 at the level of $25-28^{\circ} \mathrm{C}(\mathrm{CK}) . \mathrm{H} 12$ represents XH35 at the level of $12-15^{\circ} \mathrm{C}, \mathrm{H} 18$ represents XH35 at the level of $18-21^{\circ} \mathrm{C}, \mathrm{H} 25$ represents $\mathrm{XH} 35$ at the level of $25-28^{\circ} \mathrm{C}(\mathrm{CK})$

\section{Correlation analysis on cotton seeds germination and their physiological and biochemical indices at low temperature}

Correlation analysis of physiological parameters of cotton seeds germination are shown in Fig. 5. The activity of POD shows extremely significant and positive correlation to SOD, CAT, MDA, SP, $\mathrm{H}_{2} \mathrm{O}_{2}$, SS $(P<0.001)$, and significant and positive correlation to FP $(P<0.05)$. A significant and positive correlation between SOD and CAT, SP, $\mathrm{H}_{2} \mathrm{O}_{2}$ and $\mathrm{SS}(P<0.001)$ was observed. CAT activity was highly positively with SP, $\mathrm{H}_{2} \mathrm{O}_{2}$ and SS $(P<0.001)$, and significantly correlated with MDA $(P<0.05)$. There is an extremely significant and positive correlation between MDA and SS $(P<0.001)$; SP extremely significantly and positively correlated with $\mathrm{H}_{2} \mathrm{O}_{2}$ and SS $(P<0.001) ; \mathrm{H}_{2} \mathrm{O}_{2}$ had extremely significant and positive correlation with $\mathrm{SS}$ $(P<0.001)$.

Dry seed stage had a significant and positive correlation with $\mathrm{SP}, \mathrm{H}_{2} \mathrm{O}_{2}$, SOD and CAT (Table 5), SS $(P<0.05)$, extremely and negatively correlated with POD $(P<0.01)$, and with FP $(P<0.05)$. The rapid water absorption stage was significantly positively correlated with SP $(P<0.05)$, but significantly negatively correlated with MDA and CAT $(P<0.01)$. The slow water absorption stage had a significantly positive correlation with SP and SOD $(P<0.01)$, but highly negatively correlated with CAT $(P<0.05)$ and MDA $(P<0.01)$. Germination stage was strongly positively correlated with SP, SOD, POD and CAT $(P<0.01)$, but is extremely negatively correlated with FP $(P<0.01)$. 


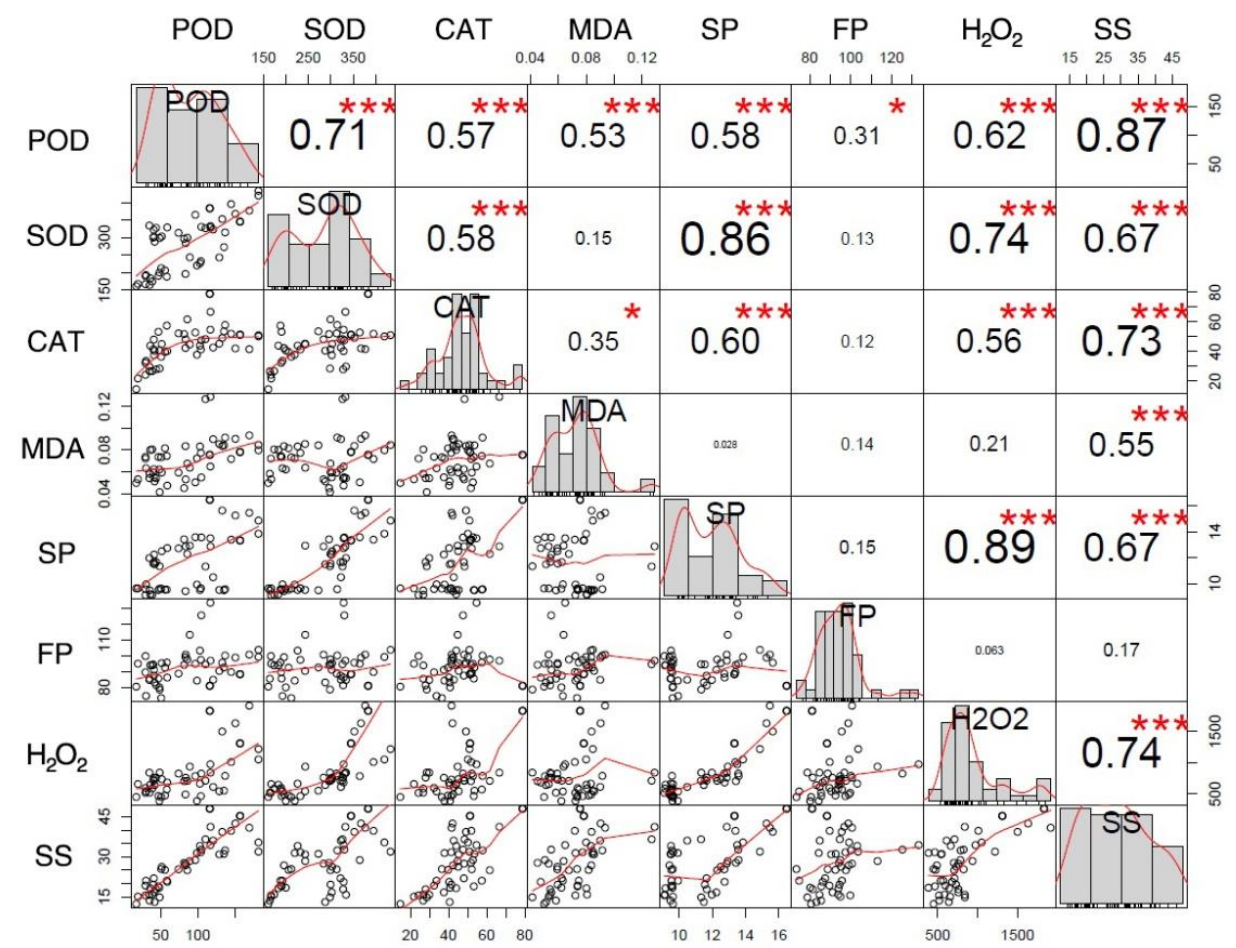

Figure 5. Correlation analysis of physiological index parameters during germination of different genotypes of cotton. The line and bars in the figure represent comparison values with a correlation coefficient of $1(r=1)$, where * represents significant $(P \leq 0.05), * *$ represents highly significant $(P \leq 0.01)$, and $* * *$ represents very significant $(P \leq 0.001)$. MDA: malondialdehyde content; SS: soluble sugar content; SP: soluble protein content; FP: free proline content; $\mathrm{H}_{2} \mathrm{O}_{2}$ : hydrogen peroxide; SOD: superoxide dismutase; $\mathrm{POD}$ : peroxidase; CAT: catalase

Table 5. Correlation coefficient between seed imbibition stage and physiological and biochemical indices

\begin{tabular}{c|c|c|c|c|c|c|c|c}
\hline Imbibition stage & MDA & SS & SP & FP & H2O $_{2}$ & SOD & POD & CAT \\
\hline Dried seeds & 0.053 & $0.520^{*}$ & $0.601^{* *}$ & $-0.526^{*}$ & $0.617^{* *}$ & $0.601^{* *}$ & $-0.594^{* *}$ & $0.621^{* *}$ \\
Rapid water absorption stage & $-0.861^{* *}$ & -0.106 & $0.496^{*}$ & -0.137 & 0.463 & 0.383 & 0.457 & $-0.857^{* *}$ \\
Slow water absorption stage & $-.716^{* *}$ & 0.204 & $0.620^{* *}$ & -0.456 & 0.306 & $0.677^{* *}$ & 0.229 & $-0.539^{*}$ \\
White period & -0.103 & 0.181 & $0.666^{* *}$ & $-0.755^{* *}$ & 0.213 & $0.690^{* *}$ & $0.746^{* *}$ & $0.651^{* *}$ \\
\hline
\end{tabular}

**Significant at the 0.01 probability level (2-tailed); *significant at the 0.05 probability level (2-tailed). MDA: malondialdehyde content; SS: soluble sugar content; SP: soluble protein content; FP: free proline content; $\mathrm{H}_{2} \mathrm{O}_{2}$ : hydrogen peroxide; SOD: superoxide dismutase; POD: peroxidase; CAT: catalase. Dried seeds showed seed imbibition initial time, Rapid water absorption stage showed start to absorb water to $12 \mathrm{~h}$, Slow water absorption stage showed seed absorb water $12 \mathrm{~h}$ to revealing radicle, White period showed the growing radicle

\section{Effect of low temperature on the variation of physiological parameters of cotton seeds germination}

The principle component analysis of eight physiological parameters, i.e. SOD, POD and CAT in cotton seeds of different genotypes was conducted; the cumulative contribution rates of the first two principal components extracted are $81.49 \%$ and 
$80.46 \%$, which are important in interpreting the total variation of the data set (Fig. 6). Principle component 1(PC1) explains the variations of $64.73 \%$ (XLZ65) and $65.59 \%$ (XH35), and can clearly distinguish different imbibition time. Principal component 2 (PC2) shows the variations of $16.76 \%$ and $14.87 \%$, and can distinguish different low temperature treatments. In principle component 1, the weight coefficients of SP, SS and PSD of Xinluzao65 were higher than 0.400 (Table 6), indicating that the imbibition time has a significant effect on SOD, POD and SS of upland cotton and SP and SS of XH35. In principal component 2, the load values of MDA and FP of L65 and FP of XH35 are greater. This indicates that FP is obviously affected by temperature.

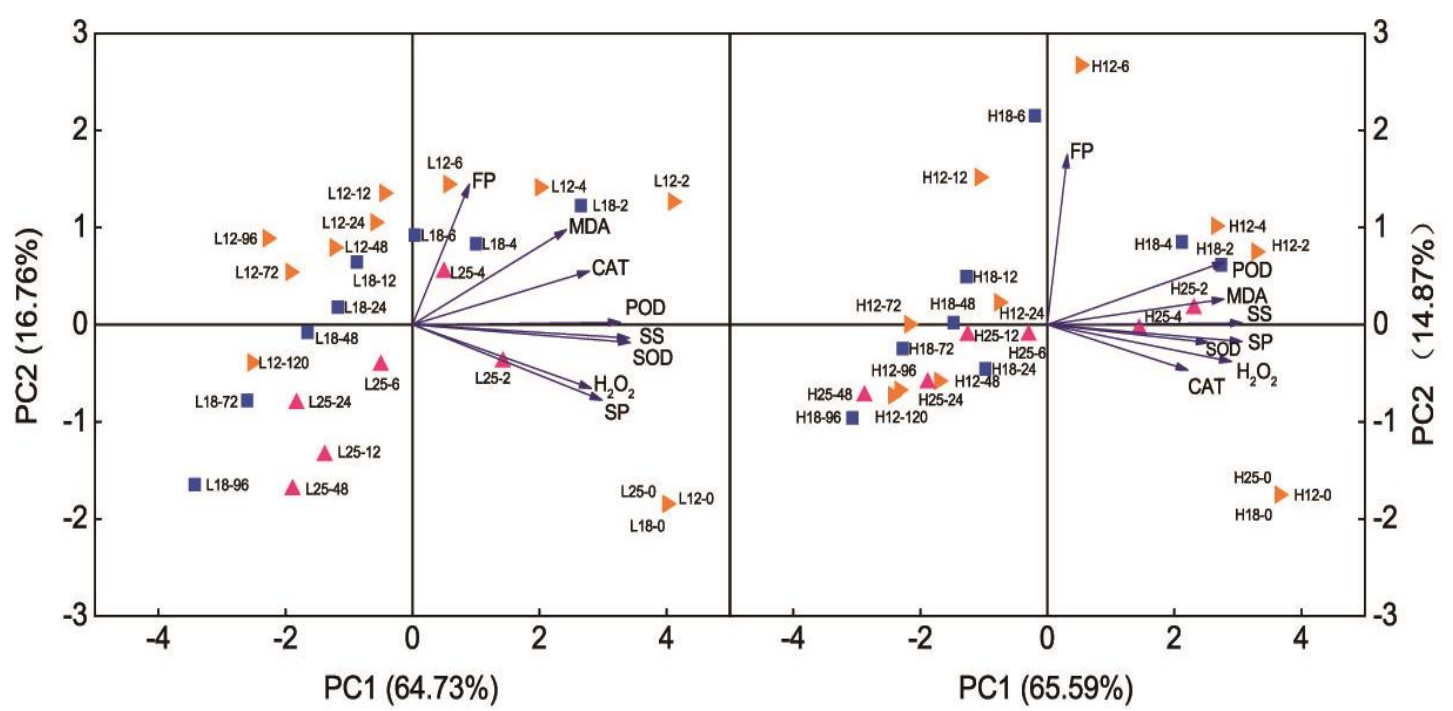

Figure 6. Principal component analysis showing the relationship of the couple of low temperature stress and genotypic differences on cotton germination parameters. The couple of seed imbibition time and physiological and biochemical indices. L showed XLZ65, H showed

XH35, 12 showed temperature $12 \sim 15^{\circ} \mathrm{C}$; 18 showed temperature $18 \sim 21{ }^{\circ} \mathrm{C}$; 25 showed temperature $25 \sim 28{ }^{\circ} \mathrm{C}(\mathrm{CK}), 0,2,4,6,12,24,48,72,96,120$ showed the cotton seed imbibition time. Soluble Sugar (SS), Soluble Protein (SP), Free Proline (FP), Malondialdehyde (MDA) and Hydrogen Peroxide $\left(\mathrm{H}_{2} \mathrm{O}_{2}\right)$, superoxide dismutase (SOD), peroxidase (POD) and catalase (CAT)

Table 6. Principal component loading matrix

\begin{tabular}{c|c|c|c|c|c}
\hline \multirow{2}{*}{ Parameter } & \multicolumn{2}{|c|}{ Extracted component (XLZ65) } & \multirow{2}{*}{ Parameter } & \multicolumn{2}{c}{ Extracted component (XH35) } \\
\cline { 2 - 3 } \cline { 5 - 6 } & PC1 & PC2 & & PC1 & PC2 \\
\hline POD & 0.405 & 0.011 & POD & 0.379 & 0.323 \\
SOD & 0.424 & -0.088 & SOD & 0.344 & -0.091 \\
CAT & 0.344 & 0.261 & CAT & 0.301 & -0.236 \\
MDA & 0.3 & 0.464 & MDA & 0.378 & 0.132 \\
SP & 0.369 & -0.369 & SP & 0.416 & -0.087 \\
FP & 0.111 & 0.686 & FP & 0.043 & 0.878 \\
$\mathrm{H}_{2} \mathrm{O}_{2}$ & 0.348 & -0.312 & $\mathrm{H}_{2} \mathrm{O}_{2}$ & 0.394 & -0.191 \\
$\mathrm{SS}$ & 0.422 & -0.065 & SS & 0.417 & 0.009 \\
\hline
\end{tabular}

MDA: malondialdehyde content; SS: soluble sugar content; SP: soluble protein content; FP: free proline content; $\mathrm{H}_{2} \mathrm{O}_{2}$ : hydrogen peroxide; SOD: superoxide dismutase; POD: peroxidase; CAT: catalase 


\section{Discussion}

Cotton seeds are susceptible to temperature in the early stages of germination. When the temperature is below $10^{\circ} \mathrm{C}$, cotton seeds fail to germinate (Kargiotidou et al., 2008). Yang (2015) shows that low temperature reduces the water absorption rate of wheat (Triticum aestivum L.) seeds, resulting in a decrease in their respiratory rate and delayed germination. This study shows that with the decrease of temperature, the water absorption rate, sprouting rate and germination index of cotton seeds of different genotypes shows a downward tendency. This indicates that low temperature influences the water absorption rate of seeds leading to reduced water intake and interferes with metabolic activities in seed embryos. As a result, germination ability of cotton seeds is decreased. Cutting watermelon (Citrullus lanatus) seed coat at low temperature can improve water absorption capacity, making it able to maintain high cold resistance and increase germination rate (Nerson et al., 1985). This study shows that with the decrease of temperature, water absorption, germination index and germination cold resistance index of XH35 were higher than those of XLZ65. Consequently, a high water absorption rate and capacity was the main reason for the strong cold resistance of Island cotton.

Active oxygen accumulation can cause chilling injuries in plants (Baek and Skinner, 2003; Xu et al., 2006). The antioxidant enzyme system plays an important role in the active oxygen injury caused by low temperature (Imahori et al., 2008; Ashraf, 2009). Zhang and Xie (2013) find that at low temperature, the activities of SOD, POD and CAT in cotton seedlings were significantly reduced, which inhibit the growth of cotton seedlings. In the current study, the activities of cotton seed enzymes under low temperatures were higher than those of control groups in normal temperature. It may be that low temperature inhibits the expression of enzyme activities in cotton seeds, delays the metabolism of storage materials and hinders the germination of cotton seeds. Ren et al. (2017) find that low temperature inhibits the enzymes involved in metabolism in peony (Paeonia suffruticosa Andr.) seeds, leading to delayed degradation of starch and other metabolites which affects glycolysis resulting in inhibition of seed germination. However, the contents of SOD and CAT in XH35 seed embryos were higher than those in XLZ65's, and after $4 \mathrm{~h}$ of low temperature treatment, the POD content of XH35 was higher than that in XLZ65, the water absorption capacity and rate of XH35 are higher than those of XLZ65, which accelerate the metabolism and transformation of substances at low temperature, increasing the germination rate of Island cotton.

Under stress conditions, soluble sugar, soluble protein and proline in plants can alleviate cell damage caused by low temperature and improve low temperature resistance of plants (Duncan and Widholm, 1987; Solomon et al., 1994). Chang et al. (2018) found that the contents of soluble sugar and soluble protein increased at low temperature, and the increase of proline in low temperature resistant varieties was large. This study shows that after low temperature treatment, the contents of soluble protein and soluble sugar were higher than those of control groups, which may delay the physiological metabolic reaction due to low temperature, causing the content to change more slowly than in normal temperature. This is consistent with previous studies (Liu et al., 2012). Soluble sugar, soluble protein and free proline contents of XH35 were higher than that of XLZ65, which is consistent with the results of the study by Mambetale et al. (2017). This is probably because of the adjustment capacity produced by the protection system of Upland cotton under stress conditions is lower than that of Island cotton. Therefore, the contents of soluble protein, soluble sugar and free proline in the embryo 
after low temperature treatment can be used as physiological indices of cold resistance of cotton seed germination.

Malondialdehyde (MDA) reflects to some extent the degree of damage to the cell membrane (Velikova et al., 2000). Gao et al. (2018) found that at low temperature, the MDA content of low temperature resistant varieties remained almost unchanged, and low temperature resistant varieties were increased. The data from this study shows that higher MDA content of XH35 after low temperature treatment was lower than XLZ65, indicating that Island cotton was less damaged by low temperature compared with Upland cotton due to its poor membrane stability. Ou-yang et al. (2007) reported that increase of $\mathrm{H}_{2} \mathrm{O}_{2}$ content in tomato (Solanum lycopersicum) peel can induce the enhancement of cold resistance of tomato. This study shows that due to the high content of $\mathrm{H}_{2} \mathrm{O}_{2}$ in $\mathrm{XH} 35$, the activities of antioxidant enzymes were enhanced, and the damage caused by low temperature stress were alleviated, thereby improving cotton seeds germination ability under low temperature.

Correlation analysis of physiological indicators of cotton seedlings that the improvement of antioxidant enzyme activity provides a favorable metabolic environment for maintaining the normal physiological balance of cells and the accumulation of soluble substances (Wu et al., 2013). This experiment shows that there is an extreme significant or significant relationship between osmotic adjustment substances content and antioxidant enzyme activities exist under high stress conditions. This indicates that by adjusting SS, SP contents and POD, SOD and CAT activities to reduce oxidative damage and osmotic balance is maintained and cold resistance of cotton seeds is improved. Numerous researchers use principal component analysis to determine the strength of resistance of test varieties in stress resistance studies (Dai et al., 2014; Gulhane and Kolekar, 2014; Farshadfar et al., 2013). Wu et al. (2012) convert 12 individual items of cotton seedling leaves at low temperature into 7 independent comprehensive indicators by principal component analysis, and use cluster analysis to objectively obtain the cold resistance of the tested varieties. In this study, the principal component analysis of eight individual indicators in cotton embryos at low temperature shows that the imbibition time has a great influence on the physiological indices of cotton seed germination, i.e. the main component 1 in Figure 5 explains variations of $64.73 \%$ (XLZ65) and $65.59 \%$ (XH35). With the increase of imbibition time, low temperature decreased SOD, POD activities and FP content. This might be of the low temperature that inhibits water absorption rate and capacity of cotton seeds, slows the transformation of metabolites, and increases content of harmful substances which depress cotton germination. However, the physiological traits of cotton seeds of different genotypes were significantly different. SOD and POD activities of Island cotton increased in the first $4 \mathrm{~h}$ of inhibition, which reduces MDA content, thus improving the cold tolerance of Island cotton.

\section{Conclusions}

Water absorption is critical in seeds germination and the absorbing speed and volume decide the speed of germination. With the decrease of temperature, a significant decrease in water absorption rate of cotton seeds of both genotypes was observed. However, water absorption rate of Xinhai35 was $14.29 \%$ higher than that of Xinluzao65. Germination rate, germination index and cold resistance index of Island Cotton rate are respectively $30.70 \%, 34.63 \%$ and $32.10 \%$ higher than those of Upland 
Cotton. As a result, Island cotton shows low temperature tolerance. As the imbibition lasts, the activity of antioxidant enzymes and contents of osmotic adjustment substances were declined. Correlation analysis that there exists significant relation between the contents of osmotic adjustment substances and the activity of antioxidant enzymes. By coordinating the 8 indices in principle component analysis, it is found that SS and FP were the main factors affecting cotton seeds germination.

Therefore, under low temperature stress, it is required for seed to increase the water absorption and water absorption rate, and to quickly reach saturation state, thereby regulating metabolic pathways such as osmotic adjustment substances and antioxidant enzymes, and starting a corresponding anti-reverse response mechanism to maintain the metabolic balance and further enhance the low temperature resistance of cotton seedlings and avoid damage during germination.

Acknowledgements. This study was funded by the National Natural Science Foundation of China (No. 31760355), the Fok Ying Tung Education Foundation (No. 151030), and Program of Youth Science and Technology Innovation Leader of The Xinjiang Production and Construction Corps (No. 2017CB005).

\section{REFERENCES}

[1] Ashraf, M. (2002): Salt tolerance of cotton: some new advances. - Critical Reviews in Plant Sciences 21(1): 1-30.

[2] Ashraf, M. (2009): Biotechnological approach of improving plant salt tolerance using antioxidants as markers. - Biotechnology Advances 27(1): 84-93.

[3] Avci, U., Pattathil, S., Singh, B., Brown, V. L., Hahn, M. G., Haigler, C. H. (2013): Cotton fiber cell walls of Gossypium hirsutum and Gossypium barbadense have differences related to loosely-bound xyloglucan. - PloS One 8(2): e56315.

[4] Baek, K. H., Skinner, D. Z. (2003): Alteration of antioxidant enzyme gene expression during cold acclimation of near-isogenic wheat lines. - Plant Science (Oxford) 165(6): 1221-1227.

[5] Bailly, C., Benamar, A., Corbineau, F., Dome, D. (1996): Changes in malondialdehyde contents and in superoxide dismutase, catalase, glutathione reductase activities in sunflower seeds related to accelerated seed aging. - Plant Physiology 97: 104-110.

[6] Barrero-Gil, J., Salinas, J. (2013): Post-translational regulation of cold acclimation response. - Plant Science - An International Journal of Experimental Plant Biology 205206(5): 48-54.

[7] Bates, L. S., Waldren, R. P., Teare, I. D. (1973): Rapid determination of free proline for water stress studies. - Plant Soil 39: 205-207.

[8] Chang, B. W., Zhong, P., Liu, J., Tang, Z. H., Gao, Y. B., Yu, H. J., Guo, W. (2019): Effect of low-temperature stress and gibberellin on seed germination and seedling physiological responses in peanut. - Acta Agronomica Sinica (1): 118-130.

[9] Chen, Q. (2003): Studies of physiologic characteristics of reaction of cucumber to low temperature and poor light. - Scientia Agricultura Sinica 36(1): 77-81.

[10] Chen, Z., Ma, H., Xia, J., Hou, F., Shi, X. J., Hao, X. Z., Abdul, H., Han, H., Luo, H. H. (2017): Optimal pre-plant irrigation and fertilization can improve biomass accumulation by maintaining the root and leaf productive capacity of cotton crop. - Scientific Reports 7(1): 17168.

[11] Dai, H. F., Wu, H., Amanguli, M., Wang, L. H., Maimaiti, A., Zhang, J. S. (2014): Analysis of salt-tolerance and determination of salt-tolerant evaluation indicators in cotton seedlings of different genotypes. - Scientia Agriculture Sinica 47(7): 1290-1300. 
[12] Duncan, D. R., Widholm, J. M. (1987): Proline accumulation and its implication in cold tolerance of regenerable maize callus. - Plant Physiology 83(3): 703-708.

[13] Farshadfar, E., Mohammadi, R., Farshadfar, M., Dabiri, S. (2013): Relationships and repeatability of drought tolerance indices in wheat-rye disomic addition lines. Australian Journal of Crop Science 7(1): 130-138.

[14] Gao, L. Y., Deng, Y. S., Han, Z. F., Kong, F. J., Shen, G. F., Li, R. Z., Yin, Y. P. (2018): Evaluation of the low-temperature tolerance of cotton varieties in the Huang-Huai region during seed germination. - Cotton Science 30(06): 36-44.

[15] Gulhane, V. A., Kolekar, M. H. (2015): Diagnosis of diseases on cotton leaves using principal component analysis classifier. - 2014 Annual IEEE India Conference (INDICON), December 11-13, Pune, India.

[16] Imahori, Y., Takemura, M., Bai, J. (2008): Chilling-induced oxidative stress and antioxidant responses in mume (Prunus mume) fruit during low temperature storage. Postharvest Biology and Technology 49(1): 54-60.

[17] Kargiotidou, A., Deli, D., Galanopoulou, D., Tsaftaris, A., Farmaki, T. (2008): Low temperature and light regulate delta 12 fatty acid desaturases (FAD2) at a transcriptional level in cotton (Gossypium hirsutum). - Journal of Experimental Botany 59(8): 20432056.

[18] Khan, A., Tan, D. K., Afridi, M. Z., Luo, H. H., Tung, S. A., Ajab, M., Fahad, S. (2017): Nitrogen fertility and abiotic stresses management in cotton crop: a review. Environmental Science and Pollution Research 24(17): 14551-14566.

[19] Kochba, J., Lavee, S., Spiegel-Roy, P. (1977): Difference in peroxidase activity and isoenzymes in embryogenic and non-embryogenic 'shamouti' orange ovular callus lines. - Plant and Cell Physiology 18(2).

[20] Kraus, T. E., Fletcher, A. R. (1994): Paclobutrazol protects wheat seedlings from heat and paraquat injury. Is detoxification of active oxygen involved? - Plant and Cell Physiology 35(1): 45-52.

[21] Lauterbach, B., Krieg, D. R., Jividen, G. (1999): Fatty acid composition of lipid fractions in germinating cotton as affected by temperature. - Proceedings of the Belt Wide Cotton Conference, Memphis, Tennessee, National Cotton Council of America, pp. 564-565.

[22] Liu, C. Y., Chen, D. Y., Gai, S. P., Zhang, Y. X., Zheng, G. S. (2012): Effects of highand low temperature stress on the leaf PS II functions and physiological characteristics of tree peony. - Chinese Journal of Applied Ecology 23(01): 133-139.

[23] Liu, X., Zhao, B., Zheng, H. J., Hu, Y., Lu, G., Yang, C. Q. (2015): Gossypium barbadense genome sequence provides insight into the evolution of extra-long staple fiber and specialized metabolites. - Scientific Reports 5: 14139.

[24] Mambetale, A., Nurbulat, L., Gao, L. L., Zhang, J. S., Tian, L. W. (2017): Effect of salt stress on growth and physiological characteristics of sea island cotton and Upland cotton cultivars. - Chin Bull Bot 52: 465-473.

[25] Mei, Y. J., Zhou, J. P., Xu, H. M., Zhu, S. J. (2012): Development of sea island cotton (Gossypium barbadense L.) core collection using genotypic values. - Australian Journal of Crop Science 6(4): 673-680.

[26] Nakano, Y., Asada, K. (1987): Purification of ascorbate peroxidase in spinach chloroplasts; its inactivation in ascorbate-depleted medium and reactivation by monodehydroascorbate radical. - Plant and Cell Physiology 28(1): 131-140.

[27] Nerson, H., Paris, H. S., Karchi, Z., Sachs, M. H. (1985): Seed treatment for improved germination of tetraploid watermelon. - HortScience 20: 897-899.

[28] Ou-Yang, L. Z., Shen, L., Chen, H. R., Fan, B., Zhang, Y., Sun, J. J., Sheng, J. P. (2007): Effects of $\mathrm{H}_{2} \mathrm{O}_{2}$ on cold tolerance and antioxidant enzyme activities of tomato by coldshock treatment. - Food Science 28(7): 31-35.

[29] Ren, X. X., Xue, J. Q., Wang, S. L., Xue, Y. Q., Zhang, P., Jiang, H. D. (2017): Proteomic analysis of tree peony (Paeonia ostii 'feng dan') seed germination affected by low temperature. - Journal of Plant Physiology 224-225: S0176161717303127. 
[30] Sawan, Z. M., Fahmy, A. H., Yousef, S. E. (2011): Effect of potassium, zinc and phosphorus on seed yield, seed viability and seedling vigor of cotton (Gossypium barbadense L.). - Archives of Agronomy \& Soil Science 57(1): 75-90.

[31] Solomon, A., Beer, S., Waisel, Y., Jones, G. P., Paleg, L. G. (2010): Effects of nacl on the carboxylating activity of rubisco from Tamarix jordanis in the presence and absence of proline-related compatible solutes. - Physiologia Plantarum 90(1): 198-204.

[32] Tian, L. W., Cui, J. P., Xu, H. J., Guo, R. S., Lin, T. (2013): Analysis of the current status of American long-staple cotton production. - World Agriculture (09): 105-110.

[33] Velikova, V., Yordanov, I., Edreva, A. (2000): Oxidative stress and some antioxidant systems in acid rain-treated bean plants: protective role of exogenous polyamines. - Plant Science (Shannon) 151(1): 0-66.

[34] Wang, J. J., Wang, D. L., Yin, Z. J., Wang, S., Fan, W. L., Lu, X. K., Mu, M., Guo, L. X., Ye, W. W., Shun, X. (2016b): Identification of the chilling resistance from germination stage to seedling stage in upland cotton. - Scientia Agriculture Sinica 49(17): 3332-3346.

[35] Wang, Q., Liu, N., Yang, X., Tu, L., Zhang, X. (2016a): Small RNA-mediated responses to low- and high-temperature stresses in cotton. - Scientific Reports 6(1): 35558.

[36] Wu, H., Hou, L. L., Shi, J. Y., Ali-yan, R. Z., Zhang, J. S. (2012): Analysis and evaluation indicator selection of chilling tolerance of different cotton genotypes. Scientia Agricultura Sinica 45(9): 1703-1713.

[37] Wu, H., Zhang, J. S., Shi, J. Y., Fan, Z. C., A, L. Y., Zhang, P., Zheng, S. (2013): Physiological responses of cotton seedlings under low temperature stress. - Acta Botanica Boreali-Occidentalia Sinica 33(1): 74-82.

[38] Wu, H., Dai, H. F., Zhang, J. S., Jiao, X. L., Liu, C., Shi, J. Y., Fan, Z. C., Aliyan, R. Z. (2014): Responses of photosynthetic characteristics to low temperature stress and recovery treatment in cotton seedling leaves. - Chinese Journal of Plant Ecology 38(10): $1124-1134$.

[39] Xu, S., Li, J., Zhang, X., Wei, H., Cui, L. (2006): Effects of heat acclimation pretreatment on changes of membrane lipid peroxidation, antioxidant metabolites, and ultrastructure of chloroplasts in two cool-season turfgrass species under heat stress. - Environmental and Experimental Botany 56(3): 274-285.

[40] Yan, Q., Zeng, Y. Q., Wang, L. R., Meng, Y. L. (2016): Response of seed vigor in different cotton cultivars under low temperature and artificial aging stress. - Cotton Science 28(2): 144-151.

[41] Yan, Q. Q., Zhang, J. S., Li, X. X., Wang, Y. T. (2019): Effects of salinity stress on seed germination and root growth of seedlings in island cotton. - Acta Agronomica Sinica (1): 100-110.

[42] Yang, W. S. (2015): Protein Expression and Respiratory Metabolism Response to Low Temperature during Wheat Seed Germination. - Shandong Agricultural University, Shandong (in Chinese).

[43] Zhang, W., Xie, J. Z. (2013): Effects of low temperature stress on resistance indices of sympodial bamboo seedlings. - Advanced Materials Research 726-731: 4241-4247. 